\title{
The application of Information Exchange Bus in Electric-power Information System
}

\author{
Wang Wenxin ${ }^{1, a^{*}}$, Zhang Weiwei ${ }^{1, b}, X^{\prime}$ Shuang ${ }^{1, c}$, Zhang Xudong $^{1, d}$ and \\ ZhouWei $^{1, \mathrm{e}}$ \\ ${ }^{1}$ No 19, Chengxin Avenue, Jiangning District, Nanjing City, Jiangsu Province, China \\ awangwenxin@sgepri.sgcc.com.cn, ${ }^{b}$ zhangweiwei3@sgepri.sgcc.com.cn, ${ }^{\circ}$ \\ xushuang@sgepri.sgcc.com.cn, ${ }^{d}$ zhangxudong@sgepri.sgcc.com.cn, ${ }^{e}$ \\ zhouwei3@sgepri.sgcc.com.cn
}

Keywords: SOA, IEC61968, bus, information isolated island

Abstract. This article studies the application of information exchange bus which is based on the SOA framework, and also mainly elaborates the principle of work of information exchange bus and its application of it on all kinds of automated information system. The information exchange bus, as a key technology, mainly solves the issue of "information isolated island" between electric power production and control area and information management area. The highly stable, secured and reliable information exchange bus is widely applied in electric-power information system by means of the one based on the 61968 serious standards, the standard process work of information management and the wide range requirements of optimizing the allocation of resources.

\section{Introduction}

By now, Chinese Power Enterprises have built a great deal of varied electric-power information system. For example, power production management system (PMS), customer information system (CIS), energy management system (EMS), distribution management system (DMS), geographic information system (GIS) and so on. These systems play a major supporting role in the production, dispatch and marketing of power companies. However, the systems service different departments in a company, and their information model is only able to be used by the system itself. This situation makes different forms of information isolated island created by the ineffective communication of systems in different departments and environments [1]. Fortunately, information exchange bus based on SOA framework in electric-power information system worked out the above problematic issue, and perfectly realized the functions and performances required by IEC 61970 and 61968. With the further promotion of distribution automation construction, State Grid Corporation of China proposes to speed up the implementation of " The Three Key Projects". They are perfecting of information exchange bus and data sharing [2], research and development of sandlizarion of power distribution terminal, constructing distribution automation training system. Therefore, the importance of the application of information exchange bus to the construction of informatization will arise gradually [3].

\section{Current Situation of Information Exchange Bus Technology}

The issue of "information isolated island" in domestic electric power enterprises grid has been existed, information exchange bus is the key technology to it which can realize the enterprise information integration. The information bus provides a powerful technical support between multiple systems interconnection operation, highly integrates decentralized base data integration in power dispatching business, so that data can be unified management and maintenance. And information exchange bus provides a good foundation for various power information systems that run efficiently.

Information exchange bus adopted the models and the interfaces from international standardization, which followed CIM models in IEC 61970 seted by the International Electrotechnical Commission. And it also followed IEC 61968 interface standards in electric power enterprise application integration, and defined model in various systems that should be shared model data. Information exchange bus 
makes model specification of data interaction in power system, and makes the content of semantic and syntax in massage that used by it. Bus system platform based on service-oriented architecture (SOA architecture) is a advancement architecture which is sustainable development design, high availability and practicability. This architecture is good enough to support the sustainable development of electric power company informatization construction. And information exchange bus technology provides standard service access for the safety standard approach, and supports data transformation across safe areas. It has solved the issue of loose coupling data interaction from the different security areas.

\section{Research of Electric power information subsystem integration}

Computer network data in the power system contain production information data and management information data, they belong to production control regions and management information regions.

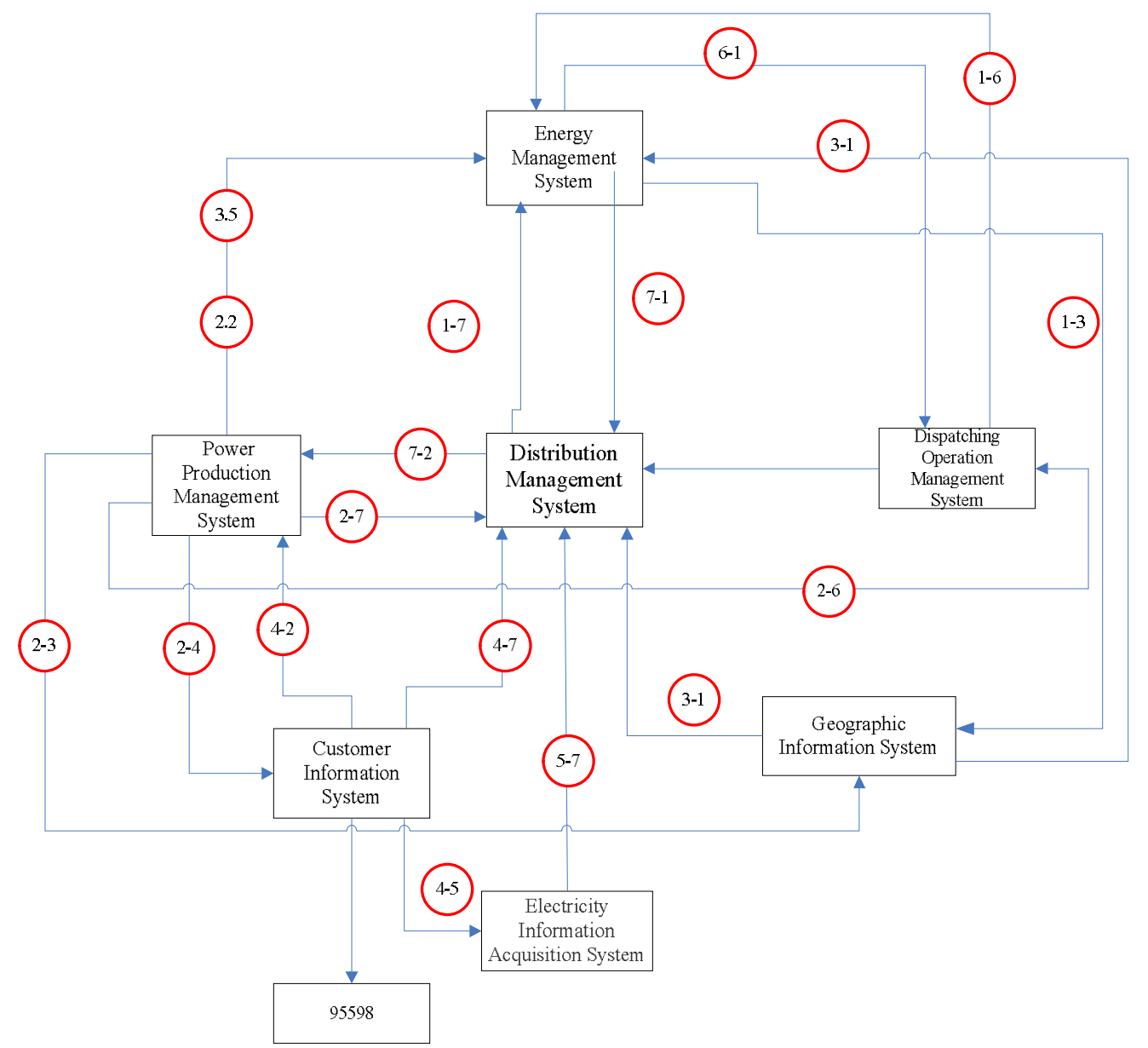

Fig. 1 Electric power information subsystem integration

Energy Management System. Energy management system (EMS) is based on computer technology of modern electric power integrated automation system, it is mainly used for big district power grid and provincial power grid, municipal power grid dispatching center. It mainly offers real-time information (including frequency, power generators, power lines and bus voltage, etc.) for power grid dispatching management grid, and manages and controls the power grid dispatching decision. EMS ensures operation safety of the power grid, and improves the quality of power grid and also improves economy of the power grid. The system can provide data and information: the grid real-time data, graphics, models, grid equipment parameter information.

Power Production Management System. Power production management system (PMS) is one of the most massive and complex applications in the eight SG186 engineering application. PMS is based on the unified application platform PI3000 build, using B/S and C/S mixed mode of multilayer (specific 
divided into the data layer, service layer and presentation layer) structure system [5].The system can provide data: distribution network equipment parameter and running management information.

Geographic Information System. Geographic information system(GIS) is an important content in the distribution automation construction. Due to mass distribution network nodes, scattered equipment, it relates to operation and management work in the geographical location, and often applies to power distribution geographic information system, so that makes operation management more intuitive. It mainly includes: equipment management (FM). The system can provide data: distribution network graph information, topological information.

Customer Information System. Customer Information System manages the customer names, address, contact person, telephone, account and cost information those belong to user data and electric properties data, and also manages computer data of electricity information power such as power load, power frequency, voltage level. On this basis, customer information system completes the electricity management functions such as meter reading, charging, electricity, industry expansion and fault repair service.

Electric power customer service system 95598 is built on a series of automation system, which collects telephone, fax, and other media of computer integrated system. If having such a system, power system can greatly make up for the inadequacy of counter service, so that customer can enjoy the high quality, efficient power service without going out.

Electricity Information Acquisition System. Electricity information acquisition system is based on the distribution transformer and end users of electricity data collection and analysis, power monitoring, implementation of ladder pricing, line loss analysis, load management, finally achieve automatic meter reading, peak electricity, electricity inspection (preventing electricity-stolen), load forecasting and save electricity costs.

Dispatching Operation Management System. Dispatching operation management system manages the information such as moving actions on the new equipment, power cut overhaul plan and defect repair order (defects) including primary side equipment, communication imperfections [6]. Application of dispatching operation management including scheduling of daily operation management, dispatching command apply for tickets issued, maintenance, operation, so that achieved the paperless office. It seems that realize dispatching automation from operation to management, and make electricity production more informatization of management, more modernization of production and more scientization of operation gradually.

Distribution Management System. Distribution Management System includes the whole distribution network, it harmonize ways of contact and coordination with the superior dispatching system, and give attention and responsibility, such as marketing, customer service support, to ensure the safe and economic operation of power grid. Need to monitor and control of power distribution automation system, therefore, information range should cover entire network as far as possible, and the information can be obtained from the existing related application system in real time or near real time measurement data, auxiliary operator to make decisions. In the overall design of information interaction, distribution automation system to the electricity information collection system the main area of statistical power information and monitoring information, and to the cable net monitor system for cable running status information, etc.

\section{Integrated Standards of Information Exchange Bus}

Distribution automation system construction using the bus information interaction of the system integration of each application system for loose coupling, register application service on the bus, can achieve the data sharing between message exchange, eliminates the traditional sense of the information island. An intelligent integration and sharing are between applications. The application system in the service registry to the front of the bus information interaction, must follow the following interactive standards, and reference bus message design specification and design code for interactive interface customization service: 
(1) Follow IEC61968 / IEC61970 common information model, the grid resource data integration design and unified modeling [7].

(2) Adopt the way of publish or subscribe when real-time or quasi real-time data information is interacted.

(3) Use the way of publish or subscribe asynchronous response mode when I/III security isolation of information is interacted.

(4) The message body use utf- 8 code to interact.

(5) The message body of encapsulation using RDF format.

(6) Use BASE64 to compression/encryption/decryption operation if necessary.

(7) Use the webservice interface between application systems and its application in the forms of interoperability between the bus and information interaction system.

\section{Data Interaction Research of Information Exchange Bus and Various Information Systems}

As a safe information interaction platform in the information automation system, information exchange bus is closely related to contact with all kinds of information service system. It is based on SOA architecture by the technology of safety data of loose coupling interaction. And a safe and efficient information bridge between production control regions and information management regions has been established. The relationship of information exchange bus and various information systems is shown in Fig2.

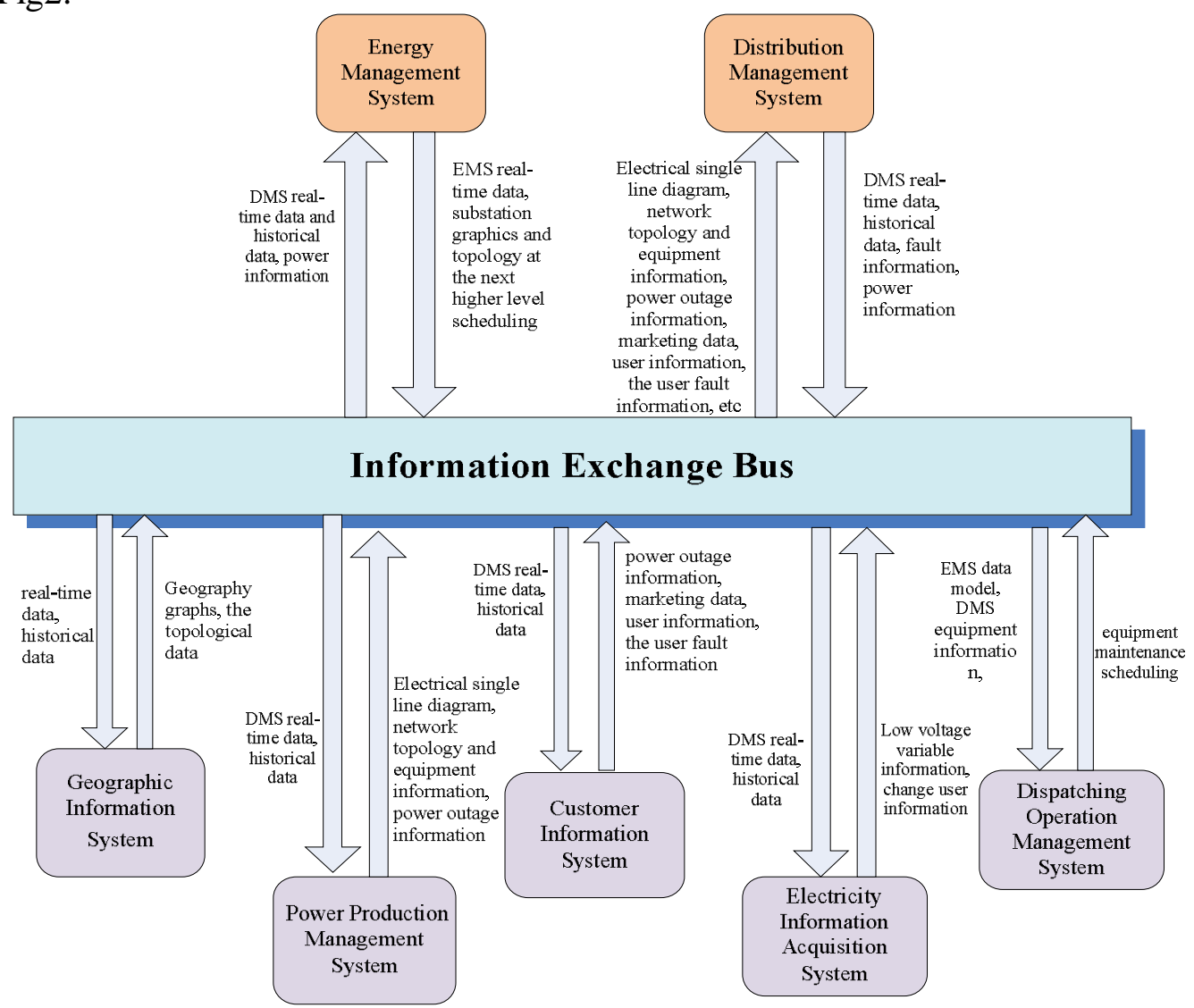

Fig. 2 The data interaction of power information systems

Energy Management System and Information Exchange Bus. Energy management system is a real-time monitoring system that maintains the grid equipment parameters and graphic topology by itself. Distribution management system subscribes the main figure model from energy management system through information exchange bus. And bus joints the EMS main figure model and distribution power model, so that forms a complete model and topology. The introduction of information exchange bus system can effectively solve the issue of repeated maintenance in grid information and share the data between the application systems. The basic parameter data input of grid work equipment which be 
unified initiated by the production management system is published to energy management system through information exchange bus.

Energy management system can publish the generated grid graph and the model to information exchange bus, and share with distribution management system.

Power Production Management System and Information Exchange Bus. As the interaction of the bridge, information exchange bus has the function of data sharing on implementation of power production management system. If the related application systems (including distribution management system) have any requirements on the equipment model information, can publish or subscribe the information needed by information exchange bus without the need to maintain.

The same requirements are needed by power system such as energy management system and customer information system. Among them, energy management system gets equipment model information from the PMS; Customer information system gets common transformer equipment information from the PMS. Information exchange bus provides the conditions to implementation for the application of the above, so that can subscribed to other power systems according to the needs of application.

Geographic Information System and Information Exchange Bus. Geographic information system provides location information of space grid structure, topology information and public attribute information, electrical equipment, and also through the information exchange bus provides available real-time monitoring of electrical equipment information from distribution management system on the way of subscription. If the related application systems (including distribution management system) have any requirements on the geographic map mode information, can subscribe the information by information exchange bus without repeated maintenance. Information exchange bus can make the geographic information system and distribution management system better integration on power grid model data.

Customer Information System and Information Exchange Bus. Customer information system publish the information including district of the electrical transformers, single transformers, user information and the relational tables; 95598 system is a functional module embedded in the customer information system, mainly subscribes user defect information and trouble ticketing information. In addition, the required common transformer equipment information in customer information system has been maintained in the PMS actually, and then the information is published through information exchange bus to customer information system, so that can reduce maintenance work, and also ensure the accuracy of the information. It conforms to the principle of information sharing of source side to maintenance.

Electricity Information Acquisition System and Information Exchange Bus. Electricity information acquisition system gathers electrical monitoring information, including current, voltage, power factor, active and reactive power, etc., that is very important for electric power production dispatching system. Electricity information acquisition system can have the effect of auxiliary decision-making on distribution management system, and provide better services within the scope of scheduling business. According to the suggestions approved by State Grid Corporation about the construction of power distribution automation, electricity information acquisition system should publish the electrical monitoring information above-mentioned through information exchange bus to distribution management system in the form of the E language.

Dispatching Operation Management System and Information Exchange Bus. Considering the particularity of dispatching operation management and the requirement of data accuracy, dispatching operation management system need to subscribe power network model to distribution management system through information exchange bus, and power distribution network model data can be subscribed by bus to the production management system.

Distribution Management System and Information Exchange Bus. Distribution management system is a real-time monitoring system of power distribution, through information exchange bus the system subscribes the main figure model from energy management system, the distribution network equipment parameter from power production management system, the distribution network diagram 
model from geographic information system, the relationship of distribution equipment code and low voltage equipment parameter (fault repair order released 95598) from customer information system, the quasi real-time distribution information from electricity information acquisition system. At the same time, distribution management system publishes real-time monitoring information to distribution network equipment. Its scope of business is the whole distribution network.

\section{Summary}

As a bridge of electrical power information interaction, information exchange bus has realized the electric power systems inside and outside the system data sharing for the major power information integration system. Information exchange bus also can provide diversified targeted interface scheme according to the features of different business system, in order to realize sharing information security point-to-point in different systems, and improve the unity of the data. Meanwhile the data flow need to interact in the different information systems has been elaborated, and we can see information exchange bus has an indispensable status in electric-power information system. So the technology of information exchange bus has important influence on power system.

\section{References}

[1] Xin Y Z. The development trend of power grid dispatching automation technology in the new century [J].Power technology, 2001, 25(12):2-5.

[2] Shen B B, Wu L, Wang P. I Distribution automation pilot project technical characteristics and application effect analysis [J] Automation of Electric Power Systems, 2012, 36(16):56-60.

[3] Zhang B, Zhao J H, Lin T. Distribution automation system research and establish standards system

[J]. Power supply On Power Systems, 2014, 5:26-29.

[4] Wang Y M.. Strong smart grid technology standard system framework [J] Automation of Electric Power Systems2010, 34(22):1-6.

[5] Cheng S J, Li X Y, Zhang ZZ. Smart grid, unified network information sharing and application of information system [J]. Proceedings of the CSEE, 2011, 31(12):8-14.

[6] Sun P S ,Cao S F, Wang Y L. State grid corporation of research and development and application of data exchange platform [J].Power System Technology, 2008, 32(22):62-67.

[7] IEC 61970-303 Common Information Model (CIM) SCADA, DR0, 1999 